\title{
Epidemiological, Diagnostic, Therapeutic and Prognostic Aspects of Melanoma of Black Skin in an African Cancer Institute
}

\author{
Sidy Ka ${ }^{1 *}$, Jean Claude Balegana ${ }^{1}$, Papa Mamadou Faye ${ }^{2}$, Doudou Diouf ${ }^{3}$, Moustapha Dieng ${ }^{4}$, Macoumba Gaye ${ }^{4}$ and Ahmadou Dem ${ }^{1}$ \\ ${ }^{1 *}$ Surgical oncologist, UCAD, Dakar University, Senegal \\ ${ }^{2}$ Resident, Dakar University, Senegal \\ ${ }^{3}$ Medical oncologist, Dakar University, Senegal \\ ${ }^{4}$ Radiation oncologist, Dakar University, Senegal
}

*Correspondence to: Sidy KA, Surgical oncologist, UCAD, Dakar University, Senegal. E-mail: sidy.ka@ucad.edu.sn

Received: November 18, 2016; Accepted: December 08, 2016; Published: December 13, 2016

\begin{abstract}
Objectives: To describe the epidemiological, clinic, histologic, therapeutic and prognosis aspects of cutaneous melanoma in African black at the Dakar cancer Institute.

Materials and methods: This was a 6 years retrospective study that included all cases of cutaneous melanoma at the Institute of Dakar cancer. The clinical, epidemiological, clinical and histological parameters as well as the treatment and prognosis were analyzed.

Results: There were 21 black skin patients with malignant melanoma. The sex ratio is 0.75 . The average age of our patients was 60.8 years and the average time of consulting, 32.8 months. The plantar melanoma accounted for $76 \%$ of cases $(n=16)$. The mean tumor size was $7.1 \mathrm{~cm}$. The presence of inguinal lymphadenopathy was noted in 12 patients or $57 \%$ of cases. Pathology showed an acral lentiginous melanoma in 18 patients or $85.7 \%$, and a nodular melanoma in 2 patients or $9.5 \%$. The Breslow thickness was more than 5 in half of the patients. Staging showed at thoraco abdominal CT, secondary locations in 9 patients (43\%). Surgical excision was performed in 8 patients while inguinal lymph node dissection was performed in 12 patients. We performed chemotherapy in 5 patients (23.8\%). Palliative haemostatic radiotherapy was successfully performed in 1 patient. The mean time follow-up was 16.1 months with extremes of 1 and 66 months. We recorded 10 deaths $(47.6 \%)$ during the period of study.
\end{abstract}

Key words: melanoma; black skin; stage; surgery; prognosis.

\section{Introduction}

Malignant melanoma is the most aggressive skin cancer with a high metastatic potential. There are 200000 new cases each year and it is the leading cause of death from skin cancer [1]. It is a rare in black people about which the skin is better protected by melanin. Surgery is the best treatment at early stage. The advent of targeted therapies and immunotherapy has improved survival in advanced cases [2]. Because of the low incidence in Africa melanoma of the black skin is understudied. The objective of this study was to report the epidemiology, diagnostic, therapeutic characteristics and outcomes of malignant melanoma of black skin at the Dakar Cancer Institute.

\section{Materials and Methods}

This was a retrospective study over a period of 6 years from January 2008 to December 2013. We evaluated the epidemiologic, clinical, histological, therapeutic and oncologic results.

\section{Results}

It was about 21 patients with malignant melanoma skin cancer of 136 cases or $15.4 \%$ of cases. They found 12 women to 9 men for a ratio of 0.75 . The average age of our patients was 60.8 years, ranging from 29 years to 85 years. The average time of consultation was 32.8 months with extremes of 4 to 108 months. All patients were black subjects. No family history of melanoma was found. Plantar melanoma accounted for $76 \%$ of cases $(n=16)$ [Figure 1]. The trunk was the second site of localization [Table 1]. The average tumor size was $7.1 \mathrm{~cm}$ with extremes of 2.5 and $15 \mathrm{~cm}$. Inguinal lymphadenopathy was noted in 12 patients (57\%). Pathotology showed an acral lentiginous melanoma in 18 patients $(85.7 \%)$ and a nodular melanoma in 2 patients $(9.5 \%)$. The Breslow thickness was more than 5 in half of the patients. Staging showed at thoraco abdominal CT secondary locations in $43 \%$ of patients $(\mathrm{n}=9), 3$ in lungs $(37.5 \%), 1$ in liver $(12.5 \%), 1$ in bones (12.5\%) and 3 cases of multiple locations (37.5\%) [Figure 2]. Surgery was performed in 14 patients or $66.7 \%$. The excision was carried out in 8 patients with macroscopic margins of $3 \mathrm{~cm}$. Amputation or dislocation was performed in 6 patients. The surgical margins were healthy in 8 patients $57 \%$ of cases. The inguinal lymph node dissection was performed in 12 patients. The average number of lymph nodes removed was 7.16 nodes with a range of 2 to 10 nodes. Node-metastasis was founds in 5 patients $(41.7 \%)$. Chemotherapy was given to 5 patients (23.8\%). Palliative haemostatic radiotherapy was successfully performed in 1 patient with melanoma of the chest wall, at a dose of 8 Gy in one session. Among the 8 patients who had secondary locations, the coup average time was 12 months. The mean follow-up was 16.1 months with extremes of 1 and 66 months. We recorded 10 deaths or $47.6 \%$ during the study period. 


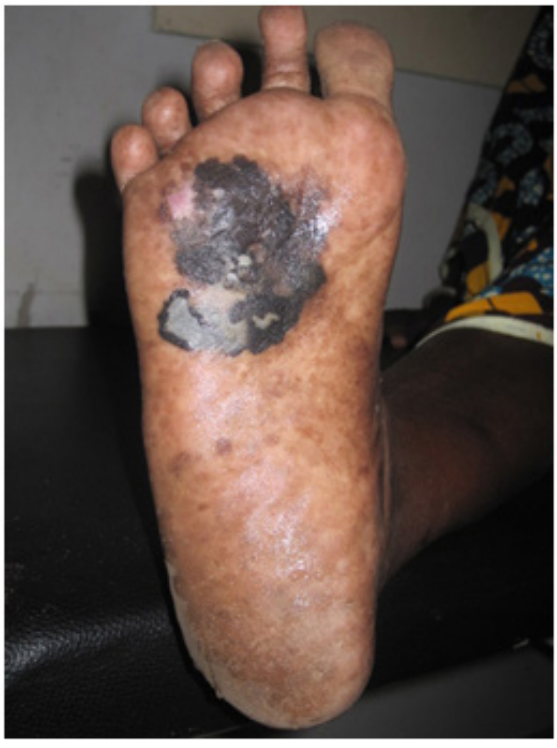

Figure 1: Plantar melanoma

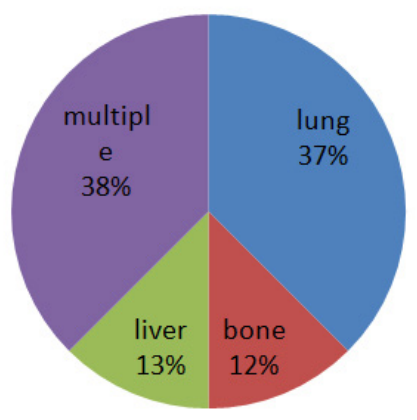

Figure 2: Different locations of metastases

Table 1. Distribution by tumor site

\begin{tabular}{|l|c|c|}
\hline & Nombre & Percentage (\%) \\
\hline Foot plant & 16 & 76 \\
\hline Trunk & 3 & 14,4 \\
\hline Right Hallux & 1 & 4,8 \\
\hline $3^{\text {rdtoe }}$ & 1 & 4,8 \\
\hline TOTAL & 21 & 100 \\
\hline
\end{tabular}

\section{Discussion}

Malignant melanoma is the most common skin cancer in light skin populations in areas where there is strong sunlight [3]. The reasons are genetic and environmental. The redhead phenotype depends on the MC1R gene and some areas like Australia are most exposed [4]. In Africa, it is less common than squamous cell carcinomas [5]. The occurrence of non-melanoma skin cancer depends on the immune status and many co-factors such as UV and HPV exposure [6]. It is an ubiquitous cancer for people aged 50 to 60. Family history plays an important role in the occurrence of melanoma [7]. Feet localizations are more frequent on black skin. It is essentially sporadic. Surveillance of plantar zone is difficult. That's probably why plantar melanoma stages are advanced and are characterized by important tumor sizes, ulceration and budding. At resection, it has a clue high Breslow. The most common histological type is acral lentiginous melanoma $[1,8]$. It is the most common form in non-caucasian, hispanic and oriental populations [5]. The cause of its preferential localization at foot plant is not yet clear. Extension of this melanoma uses lymphatic, blood and step by step ways. The extension can be done to the bones, joints and muscles of the feet; typically we can found skip metastasis along the lower limb or regional, inguinal and popliteal lymphadenopathy and even retro and under peritoneum lymph nodes. Metastases are frequently seen at diagnosis. They are most commonly lung, brain and bones [9]. The later stages characterized the diagnosis in Africa. Most of the plantar location, by diagnostic errors and traditional treatments before medical care and the limited resources of patients are seen lately. The treatment is local, loco regional and systemic and depends on the stage of the disease. The surgical resection is more effective when the Breslow thickness is low. Amputation is frequent in our conditions. The node involvement varies. The prognosis depends more on local excision in early stage of the treatment of lymph node and distant metastases [10]. In early stages, the sentinel node biopsy reduces intra operative surgical risk, post-operative complications and distance lymphedema of the lower limb $[9,11]$. Lymph node dissection in advanced stages decreases inguinal recurrence but does not change the prognosis [12]. Iliac dissection using under peritoneal route without a formal indication in non-metastatic patients, seems to improve the prognosis [13]. Advanced stages raise the problem of therapeutic choice between palliative surgery sometimes mutilating such as limb amputations in patients with poor prognosis and systemic treatment alone or no treatment. Chemotherapy slightly modified melanoma prognosis. Radiotherapy is considered rather palliative. It is preconized in adjuvant situation for large lesions and after inguinal lymphadenectomy [14]. The melanoma-related mortality in advanced stages is very high. The low socioeconomic level in Africa is therefore indirectly a poor prognosis factor. Immunotherapy with the advent of anti PD1 and anti CTLA 4 increases significantly survival of melanoma $[2,15]$.

\section{Conclusion}

Melanoma remains the most aggressive skin cancer with high metastatic potential. Its frequency in developed countries is a major public health problem. Its specific locations and socioeconomic level in black people in Africa makes the mortality very high. Surgery is more palliative than curative. Choosing a mutilating radical treatment is frequently an option. The advent of targeted therapies and immunotherapy revolutionizes its treatment and improves survival rates. Their availability is a priority in Africa.

Conflict of interest: None declared.

Source of funding: None.

Consent: Written informed consent was obtained from the patients.

Acknowledgments: None.

\section{Author Contribution:}

Ka conceived this presentation while Diouf and Dem participated in quality control of this manuscript. All authors read and approved the final manuscript. 


\section{References}

1. Erdei E, Torres SM (2010) A new understanding in the epidemiology of melanoma. Expert Rev Anticancer Ther 10: 1811-1823. [crossref]

2. Philips GK, Atkins M2 (2015) Therapeutic uses of anti-PD-1 and anti-PD-L1 antibodies. Int Immunol 27: 39-46. [crossref]

3. Grange F1 (2005) [Epidemiology of cutaneous melanoma: descriptive data in France and Europe]. Ann Dermatol Venereol 132: 975-982. [crossref]

4. Giles GG, Armstrong BK, Burton RC, Staples MP, Thursfield VJ (1996) Has mortality from melanoma stopped rising in Australia? Analysis of trends between 1931 and 1994. BMJ 312: 1121-1125. [crossref]

5. Pitche P, Tchamdja S, Napo koura G, Bakonde P et al. (1997)Les cancers cutanés en consultation dermatologique à Lomé(Togo). Méd Afr Noir 44:15-17.

6. Reusser NM, Downing C2, Guidry J3, Tyring SK4 (2015) HPV Carcinomas in Immunocompromised Patients. J Clin Med 4: 260-281. [crossref]

7. Payette MJ, Katz M 3rd, Grant-Kels JM (2009) Melanoma prognostic factors found in the dermatopathology report. Clin Dermatol 27: 53-74. [crossref]

8. Phan A, Touzet S, Dalle S, Ronger S, Balme B, Thomas L (2007) Acral lentiginous melanoma: histopathological pronostic feature of 121 cases. $\mathrm{Br} J$ Dermatol $157: 311-318$
9. Homolak D, Šitum M, Cupic H (2015) Clinico-pathological features of patients with melanoma and positive sentinel lymph node biopsy: a single institution experience. Acta Dermatovenerol Croat 23:122-9.

10. Arcangeli F, Catrani S, Greco I, Pierleoni M, Landi G (2010) Prevention and early diagnosis of melanoma: a regional experience in Italy. Jour Eur Acad Dermatol Venereo 2: 207-210.

11. Duvernay A, Henault B, Danino MA, Trost O, Dalac S, et al. (2012) [Complications associated with sentinel lymph node biopsy for cutaneous melanoma. A retrospective study of 127 patients]. Ann Chir Plast Esthet 57: 151-157. [crossref]

12. Mozzillo N, Caracò C, Marone U, Di Monta G, Crispo A, et al. (2013) Superficial and deep lymph node dissection for stage III cutaneous melanoma: clinical outcome and prognostic factors. World J Surg Oncol 11: 36. [crossref]

13. Giudice G, Robusto F, Nacchiero E (2016) The surgical treatment of a melanoma patient with macroscopic metastasis in peri and retrocaval lymph nodes and with a positive sentinel lymph node in the groin. Ann Ital Chir 4: 87.

14. Burmeister BH, Henderson MA, Ainslie J, Fisher R, et al. (2012) Adjuvant radiotherapy versus observation alone for patients at risk of lymph-node field relapse after therapeutic lymphadenectomy for melanoma: a randomised trial. Lancet Oncol 13:589-97.

15. Blank CU, Enk A (2015) Therapeutic use of anti-CTLA-4 antibodies. Int Immunol 27: 3-10. [crossref]

Citation:

Sidy Ka, Ahmadou Dem, Doudou Diouf, et al. (2016) Epidemiological, Diagnostic, Therapeutic and Prognostic Aspects of Melanoma of Black Skin in an African Cancer Institute. Cancer Stud Ther J Volume 1(2): 1-3 